\title{
Vascular Obliteration Due To Endothelial And Myointimal Growth In COVID-19
}

Jara Valtueña ( $\sim$ jara.valtuena@gmail.com )

Hospital Clínico Universitario de Valladolid https://orcid.org/0000-0002-9377-8668

Gerardo Martínez-García

Hospital Clínico Universitario de Valladolid

\section{Daniel Ruiz-Sánchez}

Hospital Clínico Universitario de Valladolid

María Garayar-Cantero

Hospital Clínico Universitario de Valladolid

\section{Carlos Dueñas}

Hospital Clínico Universitario de Valladolid

Ángel Aguado-García

Hospital Clínico Universitario de Valladolid

Jose María Prieto de Paula

Hospital Clínico Universitario de Valladolid

Pilar Manchado López

Hospital Clínico Universitario de Valladolid

\section{Research Article}

Keywords: Covid-19, living tissue, vascular physiopathology, endothelium, new therapeutic targets

Posted Date: June 5th, 2020

DOI: https://doi.org/10.21203/rs.3.rs-32241/v2

License: (c) (i) This work is licensed under a Creative Commons Attribution 4.0 International License. Read Full License 


\section{Abstract}

Background: Severe coronavirus disease 2019 (Covid-19) is a systemic multi-organ viral invasion. Previous studies found that many patients had a procoagulant state and/or severe hypoxemia with relatively wellpreserved lung mechanics. Mechanisms underlying the vascular and its surrounding tissue are not well known yet. Histological data in Covid-19 tissues' patients are still limited and mainly focused on post-mortem analysis. Since SARS-CoV-2 largely affects cutaneous tissue, we aim to examine in depth skin lesions related to Covid-19 in order to understand better how the disease might affect living tissue.

Methods: Five skin lesions from Covid-19 adult patients were selected for histological tissue examination. Vast amount of data of immunohistochemistry (IHC) and direct immunofluorescent (DIF) were part of the assessment.

Results: A common strong vasculopathic reaction pattern based on prominent vascular endothelial and myointimal cellgrowth was identified. Endothelial cell distortion generated vascular lumen obliteration and a strike erythrocyte and serum extravasation. Extensive significant vascular C4d and C3 deposition throughout vascular cell wall was also identified. A regenerative epidermal hyperplasia with tissue structure preservation was found.

Conclusions: Covid-19 could comprise an obliterative micro-angiopathy consisting on endothelial and myointimal intensive growth with complement activation. This mechanism, together with increased vascular permeability identified, could contribute to obliterative vascular lumen and hemorrhage in Covid-19. Activation of the complement and angiogenic pathways could have an important role in inducing and maintaining this vasculopathic reaction pattern. Thus, anticoagulation by itself could not completely reverse vascular lumen obliteration, with consequent hemorrhagic increased risk associated. Skin is the largest organ in the body, the most accessible one and can mirror other organs of the body. Findings of this study could contribute to a better understanding of physio-pathological mechanisms underlying SARS-CoV-2 infection on living tissue and could help further studies find potential targets for specific therapeutic interventions in Covid-19 severe patients.

\section{Introduction}

In January 2020, the World Health Organization (WHO) declared the severe coronavirus disease 2019 (Covid-19) outbreak to be a Public Health Emergency of International Concern ${ }^{1}$. Given the rapid spread of cases across the world, the new coronavirus; Severe Acute Respiratory Syndrome Coronavirus-2 (SARS-CoV-2), has caused several hundred thousand deaths worldwide. Clinical manifestations of Covid-19 such as fever, dry cough, asthenia, headache, myalgia, anosmia, diarrhea and a great recent number of skin manifestations are widely referenced $^{2-4}$.

Severe cases are mainly associated with respiratory dysfunction and generalized coagulopathy ${ }^{5-7}$. Previous postmortem lung analysis of SARS-CoV-2 demonstrated inflammation, edema and type II pneumocyte hyperplasia ${ }^{5}$, but many patients had a procoagulant state and/or severe hypoxemia with relatively well-preserved lung mechanics ${ }^{7}$. Based on observed disease patterns, Covid-19 is not just a serious respiratory viral disease, but rather a systemic multi-organ viral invasion with microvascular injury and thrombosis ${ }^{5-8}$. However recent data indicates that anticoagulated patients were more likely to require invasive mechanical ventilation with a poor outcome associated $^{9}$. Mechanisms underlying the vascular and surrounding tissue Covid-19 impact are not well known yet. Histological data are still limited and mainly focused on post-mortem analysis. There are barely any studies performed in living tissue of Covid-19 patients. 
Since SARS-CoV-2 largely affects cutaneous tissue, skin Covid-19 lesions could provide extensive information. A skin biopsy could be a very accessible procedure to assess the pathophysiologic mechanisms in depth in living tissue of Covid-19 patients. Vast clinical and histological descriptive expressions of skin on Covid-19 patients could provide insightful findings.

Herein, we aim to examine in depth skin lesions related to Covid-19. Immune and inflammatory histologic markers were evaluated in order to understand better how the disease might affect living tissue, paying particular attention to vascular effects.

\section{Methods}

Five skin lesions from caucasian Covid-19 adult patients were selected for histological tissue examination. Cutaneous lesions were manifested during the infection period and they were not associated to any other disease. Skin biopsies were conducted under patient consent. Both, punch (case 1, 3 and 5) and incisional biopsy (case 2 and 4) techniques were performed.

Routine light microscopy (Leica DM 2000 LED), IHC (Agilent Dako Omnis, Glostrup, Denmark, SN-1501004959) and DIF (Agilent Dako Autostainer, Glostrup, Denmark, SN-AS1292D0906) techniques were conducted as seen in Table 1. Hematoxylin/Eosin (HE) (Agilent Dako Coverstainer, Glostrup, Denmark, SN-CS100-10390), Iron stain (Agilent Dako Artisan, Glostrup, Denmark, SN-ALP913100), and Periodic Acid Schiff (PAS) (Agilent Dako Artisan, Glostrup, Denmark, SN-ALP913100) staining were evaluated. Briefly, density and composition of inflammatory cells, the presence of obliterative proliferative endothelitis, vascular thrombosis, recent hemorrhage (extravascular erythrocyte cells), hemosiderin and fibrin deposits were assessed. The histological study was completed with IHC and IFD techniques. IHC for CD31, Smooth-muscle Actin (SMA), Ki67, Cyclin D1 and C4d was performed on formalin-fixed, paraffin-embedded tissues using standard streptavidin-biotin peroxidase detection system (automated staining) to analyze the manifestation of vascular cell growth. The antibodies, clones and dilutions used were: CD31 (clone JC70A, Agilent Dako Glostrup, Denmark [GA61061], ready to use) was performed to identify the potential enlargement of endothelial cells. SMA (clone 1A4, Agilent Dako Glostrup, Denmark [GA61161], ready to use) was performed to analyze the myointimal capillary cells hyperplasia. Ki67 (clone MIB-1, Agilent Dako Glostrup, Denmark [GA62661] ready to use) and Cyclin D1 (clone EP12, Agilent Dako Glostrup, Denmark, IR08361, ready to use) were performed to assess the significant proliferative activity of vascular cell components. Identification of complement C4d (clone A24-T, monoclonal rabbit, Biocare Medical, Pacheco, CA, 1:50) within any elastic fibers, the elastic lamina of vessels and epithelial basement membrane zone, was considered nonspecific staining.

Identification of C3 (Policlonal rabbit anti-Human, Agilent Dako Autostainer Glostrup, Denmark, F020102, 1:20), IgM (Policlonal rabbit anti-Human, Agilent Dako Autostainer Glostrup, Denmark, F020302, 1:20), IgG (Policlonal rabbit anti-Human, Agilent Dako Autostainer Glostrup, Denmark, F020202, 1:20) and IgA (Policlonal rabbit antiHuman, Agilent Dako Autostainer Glostrup, Denmark, F020402, 1:20) deposits were evaluated by DIF.

\section{Results}

The evaluated lesions fell under pseudo-chilblain (case 1) and purpuric (cases 2 to 5 ) Covid-19 cutaneous patterns $^{4}$. Cases 1 to 3 on the fingers, case 4 on the lower limbs and case 5 on the foot of the patients (Description shown on Table 1 and Figure 1). 
All patients had presented asthenia and gastrointestinal symptoms (abdominal pain, diarrhea, nauseas or vomits) among others (Table 1). None of them had drug allergies, neither previous history of rheumatological, dermatological disease, acrocyanosis, Raynaud phenomenon, nor perniosis. Distal pulses were preserved. Among relevant data of blood sampling exam, an elevated D-dimer, IL6 and ferritin serum levels, with an increase prothrombin time (PT) were found on cases 1,3 and 4 .

Our study identified common strong histological results across all the cases.

\section{Histological common findings:}

Our findings showed a common histological pattern as visualized in Table 1. The injury's brunt was mainly focused on vascular tissue. All of them presented a vasculopathic reaction pattern with prominent vascular endothelial and myointimal cell growth (Figure 2. 1a to 5b). Endothelial cell swelling with nuclei enlargement was observed. Some cells were even detached from the vascular wall (Figure 2. 1b to 5b). The increased morphological endothelial cell distortion generated vascular lumen obliteration. Striking extravasation of erythrocytes (erythro transepidermal diapedic) with concomitant serous transudate was observed and indicated recent focal hemorrhage in the tissue (Figure 2. 1a to5b). Hemosiderin deposits were observed in case 1. Cases 1,3 and 4 did show modest inflammatory cell infiltration (Figure 2. 1a-3a,4a). This phenomenon was more severe on cases 2 and 5 (Figure 2. 2a-5a). Neither an increase in neutrophils cells nor nuclear fragmentation were identify across any of the cases. No evidence of fibrinoid vascular wall necrosis, perivascular fibrin deposits, intraluminal thrombosis or ischemic tissue necrosis, considered as signs of acute vasculitis, were manifested (Figure 2. 1a to 5b). All cases showed a regenerative epidermal hyperplasia (Figure 2. 1a,2a,3a,5a).

Interestingly, positive ICH stained for CD31 confirmed a prominent endothelial cell hyperplasia and positive stained SMA provided a moderate myointimal capillary cell hyperplasia (Figure 3. 1a-5a and 1b-5b, respectively). The result was a highly obliterative vascular lumen in all the patients. Additionally, an increased number of replicating vascular cells positive stained for Ki67 and Cyclin D1 antibodies were identified (Figure 4. $1 a-5 a$ and $1 b-5 b$, respectively). Proliferation was mainly dependent on endothelial cells and myointimal vascular cells.

An extensive significant vascular C4d and C3 deposition throughout vascular cell wall was observed (Figure 4. 1c,2c,1d). A moderate granular IgM deposition were manifested. Neither IgG nor IgA deposition was identified.

\section{Discussion}

Our findings evidence a common vasculopathic reaction pattern based on prominent vascular endothelial and myointimal growth across Covid-19 patients. In our study, the lesions observed seem to be associated to an obliterative micro-angiopathy that could be induced by SARS-CoV-2 whose target seems to be the vascular endothelial and myointimal cells with complement activation. Our results are in line with post-mortem analysis ${ }^{8,10}$. To our knowledge, there is no existing previous data that examinates in great detail infected SARS CoV-2 living tissue in order to understand the mechanisms underlying vascular and its surrounding tissue compromise.

It is suspected that Covid-19 patients may be facing a microvascular process with vascular wall cell injury. Coronavirus uses the angiotensin converting enzyme 2 (ACE2) endothelium receptor, as an entry cell point ${ }^{10-11}$. 
According to our results, this phenomenon could cause a vasculopathic reaction pattern with a marked regenerative growth of both, vascular endothelial cells and vascular myointimal cells. Additionally, extensive deposits of the complement complex C4d as well as C3 were manifested and could contribute to this vascular wall alteration.

Our findings showed that this vascular cell growth and distortion provokes the obliterative capillary lumen observed. It could lead to a secondary tissular non-acute hypoxia with a higher vascular cell growth by a feedback effect. It is highly likely that increased vascular-cell proliferation could be a distinctive characteristic of the early response to hypoxic insult ${ }^{12}$. Vascular cell proliferation is confirmed in our study by the increased numbers of replicating cells positive stained for Ki67 and Cyclin D1 found in both, vascular endothelial cells and myointimal vascular cells and directly involved in cell-cycle progression. Asthenia is a very common reported Covid-19 symptom. This symptom is also found amongst our patients. This non-acute tissular hypoxia could contribute to explain this symptom.

Ischemic signs on the tissue were not identified probably due to a non-acute hypoxia. To the contrary, it was found a regenerative epidermal hyperplasia with tissue structure preservation. Our results agree with previous postmortem lung studies of SARS-CoV-2, that also demonstrated type II pneumocyte hyperplasia ${ }^{5}$. Therefore, many patients presented a procoagulant state and/or severe hypoxemia with relatively well-preserved organ structure and mechanics.

Furthermore, our results indicated that impairment of endothelium crosstalk seems to lead to blood-vascular barrier dysfunction followed by an increased vessel permeability and erythrocyte extravasation. This phenomenon could explain the hemorrhages or ecchymosis-hematomas Covid-19 patients manifested and also seen in other tissues ${ }^{5}$. Previous post-mortem lung studies also suggest that pulmonary edema caused by capillary transudation is a common characteristic of Covid $-19^{5}$.

Microvascular endothelial cell injury could subsequently activate the clotting pathway ${ }^{7}$. Thromboembolic events have been identified in patients with Covid $-19^{6}$. Across these patients, anticoagulation treatment is used. However, emergent studies have found a positive correlation between anticoagulation and a greater overall illness severity ${ }^{9}$. According to our results, anticoagulation by itself could not completely reverse vascular lumen obliteration, with consequent hemorrhagic increased risk associated.

Vascular endothelial growth factor (VEGF) is known as the most potent inducing factor to increase angiogenesis and vascular permeability ${ }^{12}$. This, together with activation of the complement, could have an important role in inducing and maintaining Covid-19 vasculopathic reaction pattern. These observations could help find potential specific pharmacotherapy for fighting against Covid-19 severe patients.

Our work aims to emphasize, as previously reported ${ }^{10}$, the importance of incorporating living tissue biopsy when examining Covid-19 mechanisms. It could also help diagnose the disease. Since SARS-CoV-2 affects cutaneous tissue too, skin Covid-19 lesions could provide extensive, accessible information and can mirror other organs of the body. Vast clinical and histological descriptive expressions of skin on Covid-19 patients could provide insightful findings to improve the diagnosis and management of the disease.

\section{Conclusions}


Based on our results, Covid-19 could include a microvascular injury consisting on endothelial and myointimal intensive growth with complement activation. This mechanism, together with increased vascular permeability, could contribute to obliterative vascular lumen and hemorrhage in Covid-19. Therefore, activation of the complement and angiogenic pathways could have an important role in inducing and maintaining this vasculopathic reaction pattern. Moreover, anticoagulation treatment might be reviewed. Findings of this study could contribute to a better understanding of physio-pathological mechanisms underlying SARS CoV- 2 infection on living tissue and could help further studies find potential targets for specific therapeutic interventions in Covid19 severe patients.

\section{Declarations}

Funding sources: None

Conflicts of Interest: The authors have no conflicts of interest.

\section{Acknowledgments:}

Many thanks especially to Erika Barrio, Rosa María García and María Teresa Valdajos for their contribution to laboratory work and to Dr. Inmaculada Gil, Dr. Laura Cardoso, Dr. Jose Enrique Campillo and Lara García Hernández for their support.

Contributions of each author: JV designed and conducted the study. GMG performed histological analysis. JV, DRS and MGC contributed to data collection. JV wrote the paper. JV and AAG contributed to figures edition. JV, GMG, MGC, CD, JMP and PML reviewed and contribute to the manuscript final edition. All authors approved final manuscript.

Data and materials availability: All data is available in the main text

\section{References}

1. Sohrabi C, Alsafi Z, O'Neill N, et al. World Health Organization declares global emergency: A review of the 2019 novel coronavirus (COVID-19). Int J Surg. 2020;76:71-76.

2. Huang C, Wang Y, Li X, et al. Clinical features of patients infected with 2019 novel coronavirus in Wuhan, China. Lancet. 2020; 395: 497-506.

3. Landa N, Mendieta-Eckert M, Fonda-Pascual P, Aguirre T. Chilblain-like lesions on feet and hands during the COVID-19 Pandemic. Int J Dermatol. 2020;59(6):739-743.

4. Galván Casas C, Català A, Carretero Hernández G, et al. Classification of the cutaneous manifestations of COVID-19: a rapid prospective nationwide consensus study in Spain with 375 cases. [published online ahead of print, 2020 Apr 29]. Br J Dermatol. 2020;10.1111/bjd.19163.

5. Zhang H1, Zhou P2, Wei Y1, et al. Histopathologic Changes and SARS-CoV-2 Immunostaining in the Lung of a Patient With COVID-19. Ann Intern Med. 2020;172(9):629-632.

6. Wichmann D, Sperhake JP, Lütgehetmann M, et al. Autopsy Findings and Venous Thromboembolism in Patients With COVID-19: A Prospective Cohort Study. Ann Intern Med. 2020 May 6. DOI: 10.7326/M20-2003. 
7. Zhou F, Yu T, Du R, et al. Clinical course and risk factors for mortality of adult inpatients with COVID-19 in Wuhan, China: a retrospective cohort study. Lancet. 2020;395(10229):1054-1062.

8. Ackermann M, Verleden SE, Kuehnel M, et al. Pulmonary Vascular Endothelialitis, Thrombosis, and Angiogenesis in Covid-19 [published online ahead of print, 2020 May 21]. N Engl J Med. 2020;10.1056/NEJMoa2015432.

9. Llitjos J, Leclerc M, Chochois $C$, et al. High incidence of venous thromboembolic events in anticoagulated severe COVID-19 patients.J Thromb Haemost. 2020 Apr 22. DOI:1111/jth.14869.

10. Magro C, Mulvey J, Berlin D, et al. Complement associated microvascular injury and thrombosis in the pathogenesis of severe covid-19 infection: A report of five cases. Transl res. 2020 Apr 15. DOI:

10.1016/j.trsl.2020.04.007.

11. Hamming I, Timens W, Bulthuis ML, Lely AT, Navis G, van Goor H. Tissue distribution of ACE2 protein, the functional receptor for SARS coronavirus. A first step in understanding SARS pathogenesis. J Pathol. 2004;203(2):631-637.

12. Apte RS, Chen DS, Ferrara N. VEGF in Signaling and Disease: Beyond Discovery and Development. Cell. 2019;176(6):1248-1264.

\section{Table 1}

Table 1. Relevant clinical characteristics and histological findings across all cases.

\begin{tabular}{|c|c|c|c|c|c|}
\hline & CASE 1 & CASE 2 & CASE 3 & CASE 4 & CASE 5 \\
\hline \multicolumn{6}{|l|}{ CLINICAL FEATURES } \\
\hline Size of the injury & Focal & Extensive & Focal & Extensive & Focal \\
\hline Anatomic affected area & Hand & Hand & Hand & $\begin{array}{l}\text { Lower } \\
\text { limbs }\end{array}$ & Foot \\
\hline $\begin{array}{l}\text { Skin lesion time-course } \\
\text { (days) }\end{array}$ & 12 & 5 & 8 & 7 & 5 \\
\hline Hemorrage aspect & YES & YES & YES & YES & YES \\
\hline Preceding Fever & YES & NO & YES & YES & NO \\
\hline \multirow[t]{2}{*}{ Other relevant symptoms } & Pneumonia & Asthenia & Pneumonia & \multirow{2}{*}{$\begin{array}{l}\text { Asthenia } \\
\text { Abdominal } \\
\text { pain }\end{array}$} & Asthenia \\
\hline & $\begin{array}{l}\text { Asthenia } \\
\text { Abdominal } \\
\text { pain }\end{array}$ & $\begin{array}{c}\text { Hand } \\
\text { edema Diarrhea, } \\
\text { Chest pain }\end{array}$ & $\begin{array}{l}\text { Asthenia } \\
\text { Diarrhea }\end{array}$ & & $\begin{array}{l}\text { Abdominal } \\
\text { pain }\end{array}$ \\
\hline $\begin{array}{l}\text { Were these general } \\
\text { symptoms present at } \\
\text { biopsy time? }\end{array}$ & NO & YES & NO & YES & YES \\
\hline $\begin{array}{l}\text { Medical state at biopsy } \\
\text { time }\end{array}$ & Fair & Fair & Fair & Fair & Fair \\
\hline
\end{tabular}

\section{HISTOLOGIC FEATURES}

\begin{tabular}{l|ccccc}
\hline Acute vasculitis & - & - & - & - & - \\
\hline Inflammatory cell density & + & +++ & + & + & ++ \\
\hline Lymphocytes cell density & + & +++ & + & + & ++ \\
\hline Neutrophils cell density & - & - & - & - & - \\
\hline & & Page 7/12 & &
\end{tabular}




\begin{tabular}{l|ccccc} 
Macrophages cell density & + & ++ & ++ & + & + \\
\hline $\begin{array}{l}\text { Obliterative proliferative } \\
\text { endothelitis }\end{array}$ & +++ & +++ & +++ & +++ & +++ \\
\hline Capillary thrombosis & - & - & - & - & - \\
\hline $\begin{array}{l}\text { Extravascular erythrocyte } \\
\text { cells (Recent hemorrhage) }\end{array}$ & +++ & ++ & ++ & ++ & +++ \\
\hline Hemosiderin deposits & + & - & - & - & - \\
\hline Fibrin deposition & - & - & - & - & - \\
\hline $\begin{array}{l}\text { Endothelial cell } \\
\text { hyperplasia (CD31 } \\
\text { stain) (IHC) }\end{array}$ & +++ & +++ & ++ & +++ & +++ \\
\hline $\begin{array}{l}\text { Myointimal cell } \\
\text { hyperplasia (SMA stain) } \\
\text { (IHC) }\end{array}$ & ++ & ++ & ++ & ++ & ++ \\
\hline $\begin{array}{l}\text { Ki67 vascular cell } \\
\text { proliferative activity (IHC) }\end{array}$ & +++ & +++ & +++ & +++ & +++ \\
\hline $\begin{array}{l}\text { Cyclin D1 vascular cell } \\
\text { proliferative activity (IHC) }\end{array}$ & $\mathbf{+ + +}$ & $\mathbf{+ + +}$ & +++ & +++ & +++ \\
\hline $\begin{array}{l}\text { Endothelial C4d deposits } \\
\text { (IHC) }\end{array}$ & $\mathbf{+ + +}$ & $\mathbf{+ + +}$ & $\mathbf{+ + +}$ & $\mathbf{+ + +}$ & ++ \\
\hline $\begin{array}{l}\text { Endothelial C3 deposits } \\
\text { (DIF) }\end{array}$ & $\mathbf{+ + +}$ & $\mathbf{+ + +}$ & +++ & +++ & +++ \\
\hline $\begin{array}{l}\text { Endothelial IgM deposits } \\
\text { (DIF) }\end{array}$ & ++ & ++ & ++ & ++ & ++ \\
\hline $\begin{array}{l}\text { Endothelial IgG deposits } \\
\text { (DIF) }\end{array}$ & - & - & - & - & - \\
\hline $\begin{array}{l}\text { Endothelial IgA deposits } \\
\text { (DIF) }\end{array}$ & - & - & - & - & - \\
\hline
\end{tabular}

Table 1 legend: - (negative result/no presence of cells), + (low), ++ (moderate), +++ (high)

\section{Figures}



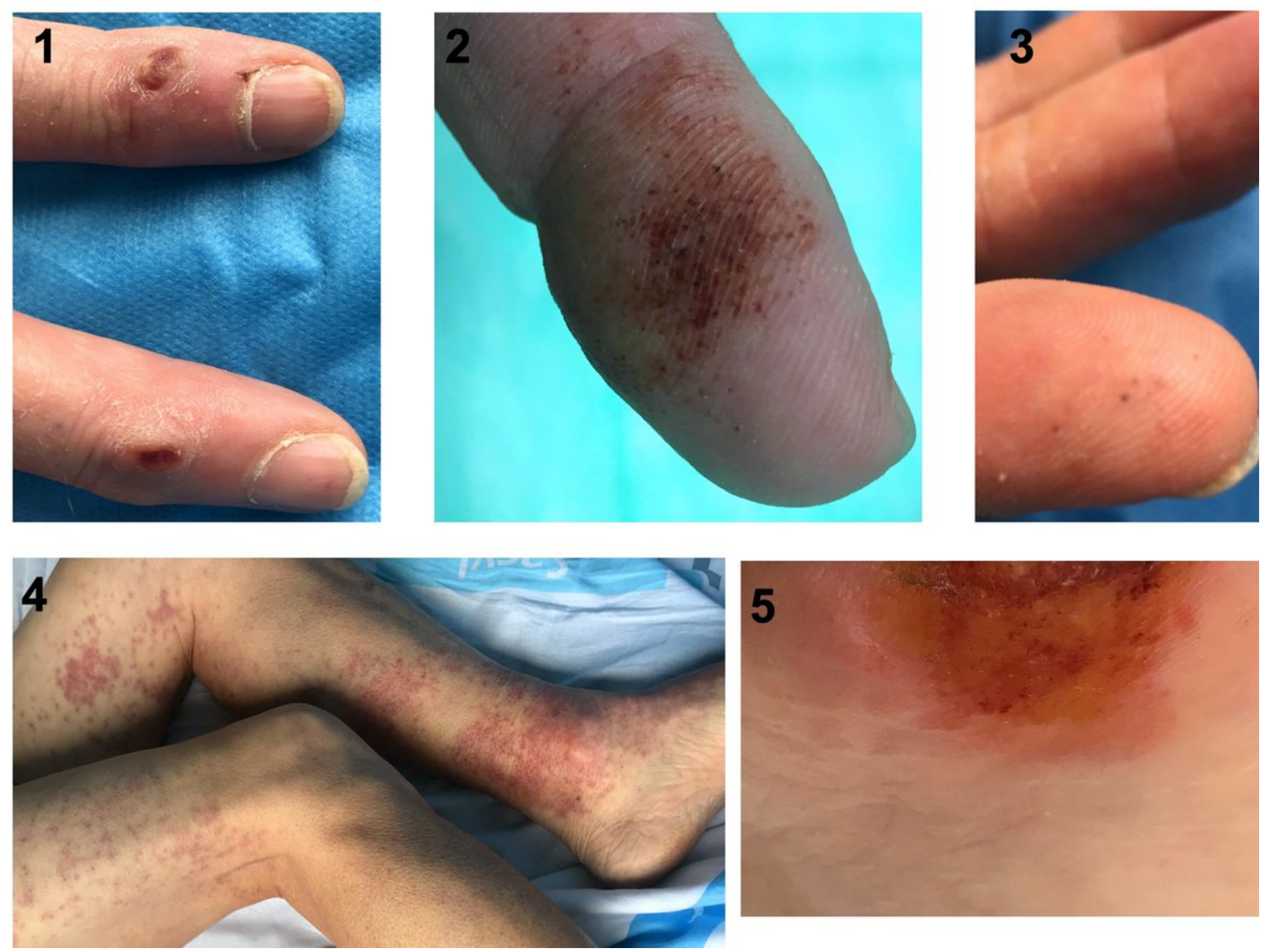

\section{Figure 1}

Covid-19 induced several clinical cutaneous patterns. Cases are present as 1 to 5 according to the text and figures. 1) case 1: two unpainful solitaries $7 \times 5 \mathrm{~mm}$ well-circumscribed flaking lesions with a brown-purple lesion 2) case 2: Multiple darkpurple painful micro-petechiae on the acral areas of the whole left-hand fingers. 3) case 3: unpainful micropetechiae on the second finger pad of the left hand 4) case 4: multiple non-palpable unpainful macular purple lesions in both lower limbs. Not bleaching when being pressure 5) 5. case 5: hematic not wellcircumscribed painful lesion on the right foot. 

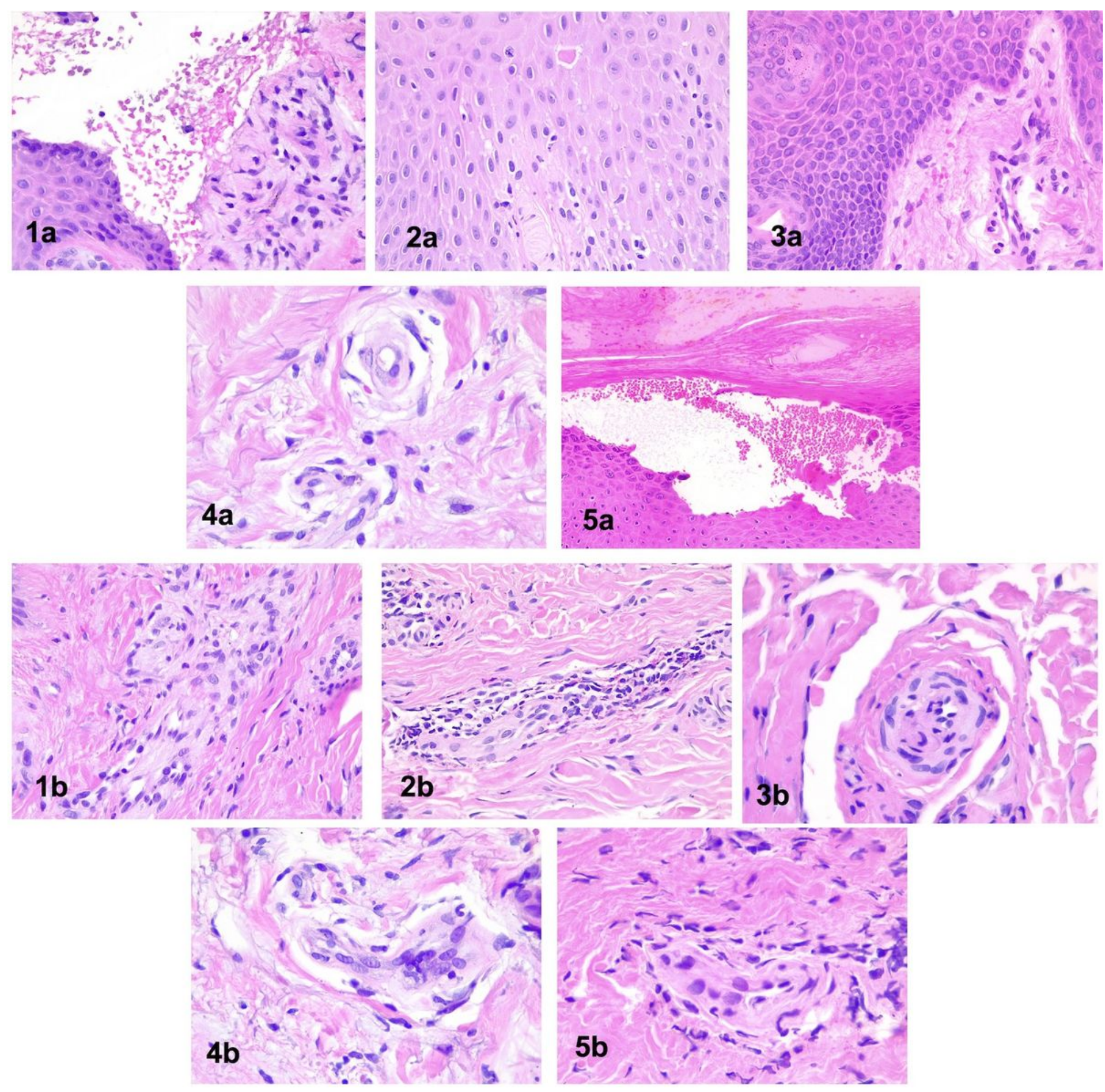

\section{Figure 2}

Microscopic features of live tissue samples from Covid- 19 patients. All the cases are shown, listed 1 to 5 according to text and figure 1 . $1 \mathrm{a}$ to $5 \mathrm{~b}$, Common strong vasculopathic reaction pattern with prominent vascular endothelial cells growth is identified. Significant erythrocyte and serum extravasation with lead to a marked hemorrhage. Modest to high inflammatory cell infiltration observed. No evidence of acute vasculitis seen (Hematoxylin and eosin stain (H/E), 4x,20x,40x,63x). 1a,2a,3a,5a, Regenerative epidermal hyperplasia shown (H/E stain 20x,40x and 63x). 1b- 5b, Endothelial cell swelling with nuclei enlargement. Some cells were even detached from the vascular wall. A highly vascular lumen obliteration is observed (H/E stain 40x and 63x). 


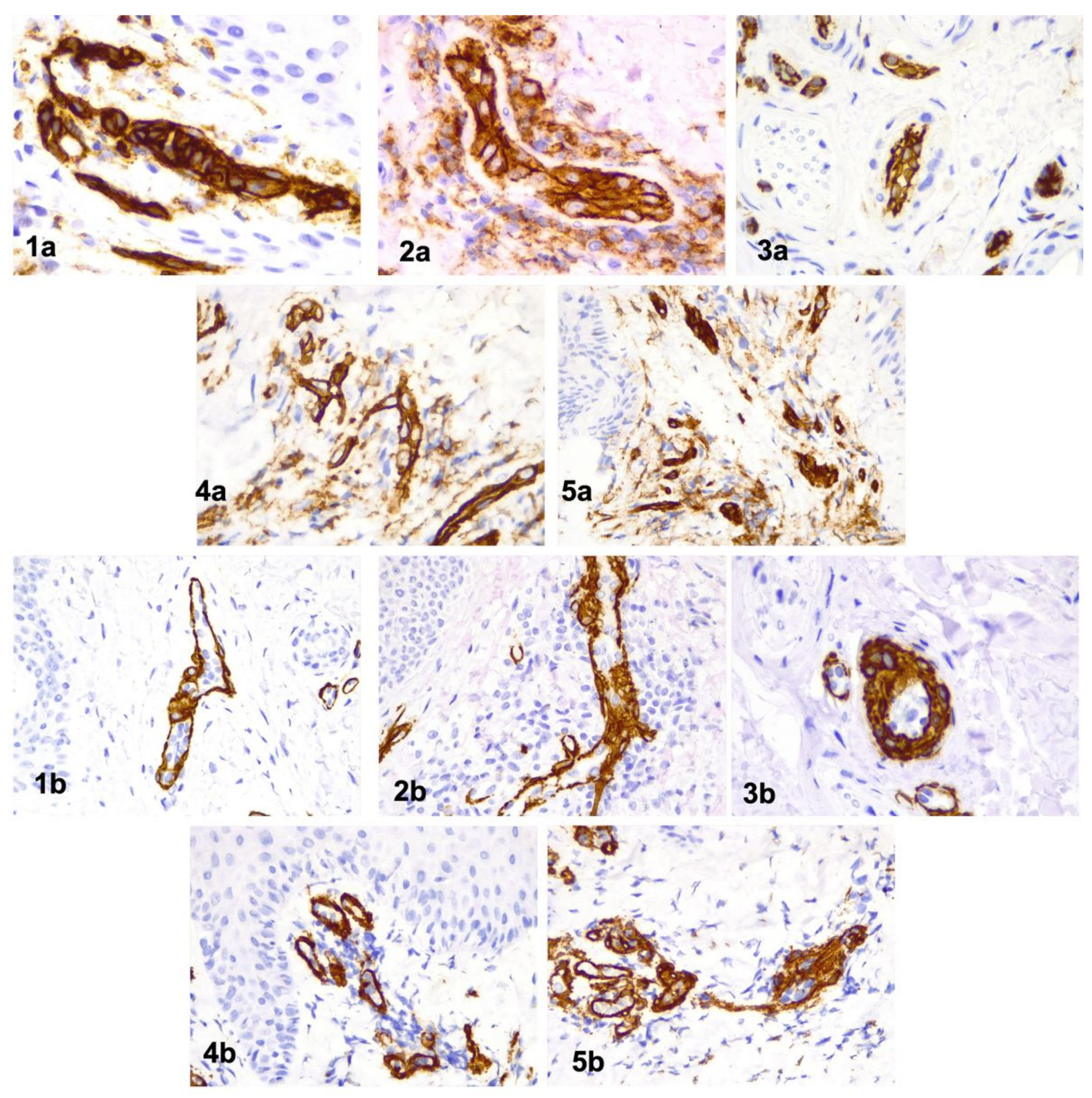

\section{Figure 3}

IHC analysis for C31stain (1a-5a) and SMA stain (1b-5b) of live tissue samples from Covid-19 patients. All the cases are shown, listed 1 to 5 according to text and figure 1 . A highly obliterate vascular lumen is observed. $1 \mathrm{a}-5 \mathrm{a}$, prominent endothelial cell hyperplasia, positive stained for C31 (CD32 stain 40x and 63x). 1b-5b, moderate myointimal vascular smooth muscle cells hyperplasia positive stained for SMA (SMA stain 40x and 63x). 

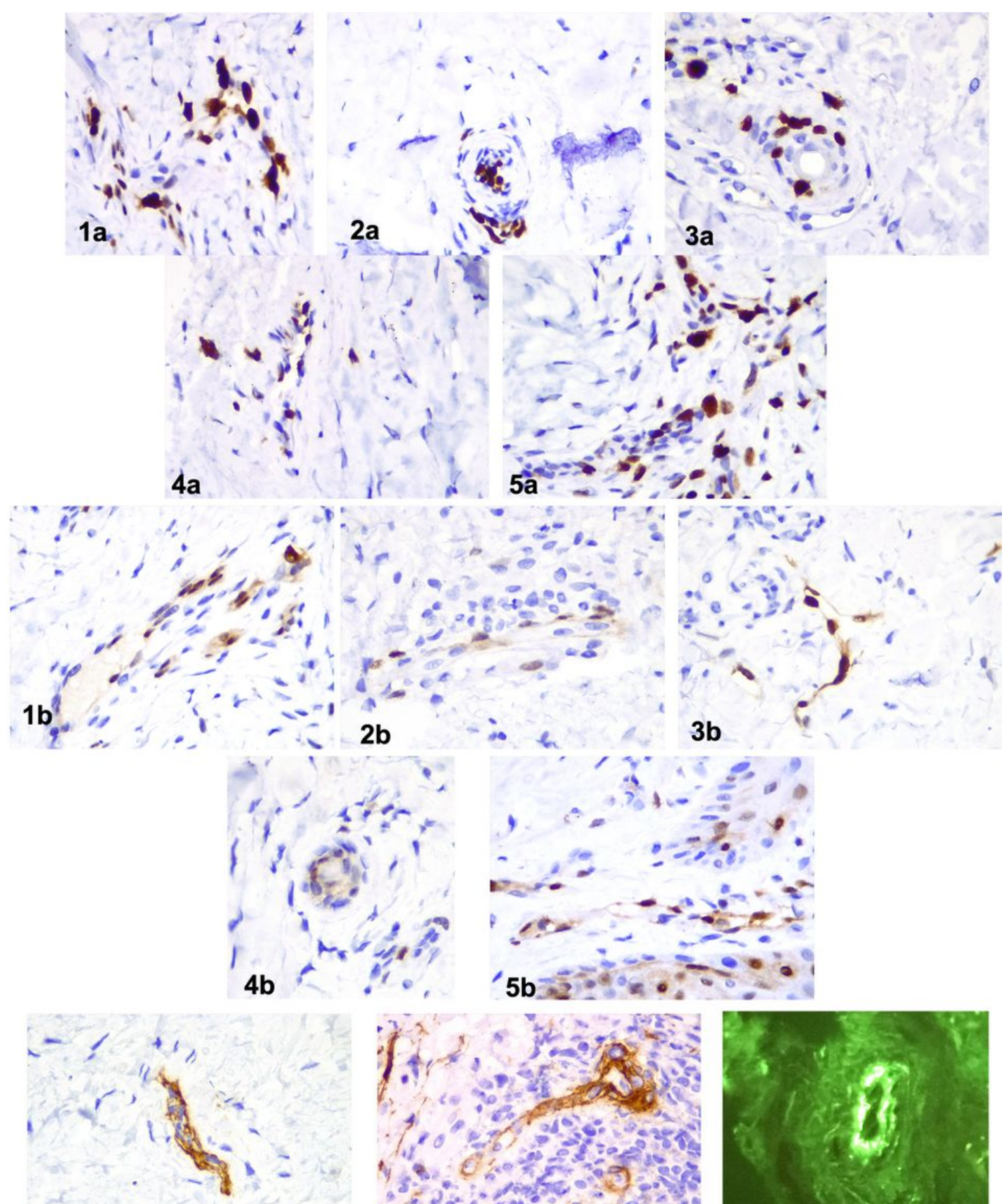

$1 c$

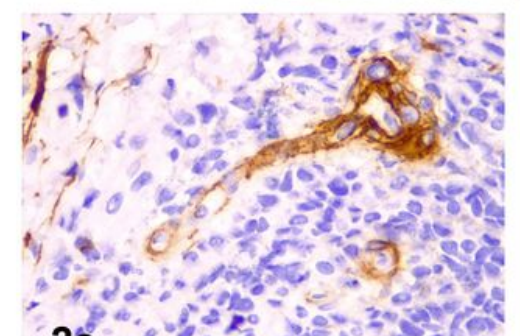

$2 \mathrm{C}$

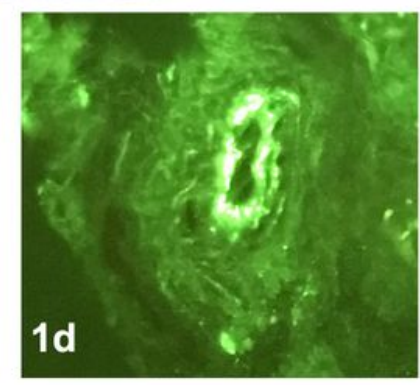

Figure 4

IHC analysis (Ki67, Cyclin D1 and C4d stain) and DIF (C3 stain) of live tissue samples from Covid-19 patients. All the cases are shown, listed 1 to 5 according to text and figure 1. A highly obliterate vascular lumen is observed in all figures. 1a-5a, an increased number of replicating endothelial and myointimal vascular smooth muscle cells, positive stained for Ki67 (Ki67 stain 63x). 1b-5b, an increased number of replicating of replicating endothelial and myointimal vascular smooth muscle cells, positive stained for Cyclin D1 (Cyclin D1 stain 63x). 1c and 2c, extensive significant endothelial C4d deposition (C4d stain 63x). 1d, extensive significant endothelial C3 deposition (C3 stain 40x). 